\section{Research Square}

Preprints are preliminary reports that have not undergone peer review. They should not be considered conclusive, used to inform clinical practice, or referenced by the media as validated information.

\title{
Train-the-Trainer Course for General Practitioners Identified Salient Points for Promoting Healthy Ageing - A Convergent Mixed-Methods Study
}

\section{Daya Yang}

Sun Yat-sen University First Affiliated Hospital

\section{Gang Yuan}

Sun Yat-sen University First Affiliated Hospital

Hao Tang

Sun Yat-sen University First Affiliated Hospital

Anne-Marie Hill

Curtin University Faculty of Health Sciences

\section{Wei Chen}

Sun Yat-sen University First Affiliated Hospital

\section{Jingsong Wang}

Sun Yat-sen University First Affiliated Hospital

\section{Ming Kuang}

Sun Yat-sen University First Affiliated Hospital

\section{Haipeng Xiao}

Sun Yat-sen University First Affiliated Hospital

Dan Xu ( $\nabla$ daniel.xu@curtin.edu.au )

Curtin University

\section{Research article}

Keywords: General practice, train-the-trainer course, health promotion, healthy ageing

Posted Date: May 22nd, 2020

DOl: https://doi.org/10.21203/rs.3.rs-28401/v1

License: (c) (i) This work is licensed under a Creative Commons Attribution 4.0 International License. Read Full License 


\section{Abstract}

Background General practitioners (GPs) in China are playing an increasingly important role in geriatric care. In the context of GP training in geriatrics, the current study sought to explore the perception of local GP trainers regarding how GP training can better serve the purpose of healthy ageing promotion.

Methods In this convergent mixed-methods design study, a convenience sample of local senior GP trainers were enrolled in a Train-the-Trainer (TTT) course in Guangzhou China. A series of lectures was conducted and followed by individual surveys via an on-line platform at the end of the course with participants providing quantitative and qualitative feedback. Course satisfaction ratings and salient points with respect to the gaps and needs for GP trainers were recorded regarding healthy ageing promotion.

Results Participants $(n=20)$ reported high levels of overall satisfaction with the course $(91.3 \%)$, and rated the course as relevant (97.5\%) and contemporary (up-to-date) (96.7\%).

Six geriatric-related topics were presented: (1) polypharmacy and de-prescribing, (2) dementia, (3) antibiotic stewardship, (4) fall prevention and frailty assessment, (5) vaccination, (6) atrial fibrillation. Participants identified salient points for inclusion into GP training programs in each topic. These salient learning points were categorized into personal, interpersonal, and societal domains.

Conclusions The TTT course for GP trainers provided an excellent platform for academic exchange regarding healthy ageing promotion. Salient points identified from course feedback may inform future training, research and collaboration initiatives for GPs' roles as health advocate for the older adult population.

\section{Introduction}

Recent years have seen an increasing level of interests and emphasis on the promotion of health in the older adult population. A variety of similar concepts have been proposed, including active ageing[1], successful ageing[2-4], positive ageing[5], and productive ageing[6]. Active ageing is defined by the World Health Organization (WHO) as "the process of optimizing opportunities for health, participation and security to enhance quality of life as people age" so as to "realize their potential for physical, social, and mental well-being throughout the life course"[1].

According to the Joint Research Centre of the European Commission, there are six key determinants that influence active and healthy ageing: economic determinants, health and social service systems, physical environment, social environment, cultural and personal determinants, and behavioural determinants[7]. In other words, healthy ageing is a lifelong process that requires holistic care for the older adult[8]. In light of this, general practitioners (GPs), the first line of healthcare workers, should play a critical role in healthy ageing promotion, for example, by designing and implementing preventive services for older adults[9]. General practitioners (GPs) in China are playing an increasingly important role in geriatric care[10]. 
However, in the context of training the next generation of GPs, what specific areas that need to be addressed, including the gaps and needs for the promotion of healthy ageing, remains to be defined.

Our current study used a train-the-trainer (TTT) course that was a joint collaboration of the First Affiliated Hospital of Sun Yat-sen University in China and Curtin Medical School of Curtin University in Australia as an academic platform, and sought to explore the perception of local GP trainers with regards to how the training of GPs can better serve the purpose of healthy ageing promotion.

\section{Methods}

\section{Study Design}

This study employed a convergent parallel mixed-methods design. The qualitative component of this study was epistemologically grounded in social constructivism[11], on the premise that promotion of healthy ageing in the context of GP training takes place as GPs construct meanings through their social interactions. This epistemological position aligns with the theoretical perspective that through personal interactions and relationships between trainers and trainees, both of whom contribute to the negotiation of a shared understanding of gaps and needs for promoting healthy ageing in the Chinese context. We aimed to understand how multiple interpretations of reality were related to the roles and processes of GP trainers as health advocates. As such, a thematic framework analysis of individual opinions was used[12]. The quantitative phase of the study used a survey design to gather feedback about the course relevance and suitability.

The study was conducted in the in First Affiliated Hospital of Sun Yat-Sen University in Guangzhou in June 2019.

\section{Ethics and Study Participants}

This study was approved by ethics committees both in First Affiliated Hospital of Sun Yat-sen University and Curtin University. A convenience sample of local 20 GP trainers were recruited in this study. All participants provided written informed consent.

\section{Train-the-trainers Course}

First Affiliated Hospital of Sun Yat-sen University in China and Curtin Medical School of Curtin University in Australia jointly organized a train-the-trainers (TTT) course for senior GP trainers in Guangzhou, China. The course consisted of a series of lectures selected by trainees and tailored to be relevant to healthy ageing promotion in the primary care setting, (rather than through a hospitalist or specialist perspective). The sessions were presented by Prof. Dan XU from Curtin University and included interactive discussions at the conclusion of the formal lectures.

\section{Data Collection and Analysis}


Immediately upon completion, participants were asked to provide feedback during the after-class group discussion and also through an online survey platform. Content of feedback sought included course satisfaction ratings (quantitative data) and salient points regarding the promotion of healthy ageing in the context of teaching GP trainees (qualitative data). For satisfaction, participants provided ratings under the following four domains: minimal prior knowledge ("Was course content known to you before?" Minimally known/ Partially known/ Fully known), content relevance ("Was the course content relevant to your practice?" Not relevant/ Mostly relevant/ Entirely relevant), content being up-to-date ("Was the course content up-to-date?" No/ Basically yes/ Yes) and overall satisfaction ("Were you satisfied with the course in general?" Unsatisfied/ Basically satisfied/ Satisfied). Participants also discussed their reflections and ideas regarding salient points in terms of gaps and needs for GP trainers in teaching GP trainees with respect to promoting healthy ageing. Quantitative data were analyzed using descriptive statistics. Qualitative data were processed through thematic analysis in order to develop descriptive themes and analytical themes[12]. This method of thematic analysis is useful in analyzing relatively unstructured, text-based data in a rigorous and inclusive fashion[13]. Results were subsequently presented as graphs or figures for quantitative data, and quotes and matrices for qualitative data. SPSS version 22 (IBM SPSS Statistics, IBM Corp, New York: USA) was used for all statistical analyses.

\section{Results}

\section{Study Participants and Relevant Topics}

All study participants $(n=20)$ were senior general practitioners in community health centres or clinics in Guangzhou city, who were actively involved in the training of GP trainees. Six modules were delivered during the course that covered the following topics: (1) polypharmacy and de-prescribing, (2) dementia, (3) antibiotic stewardship, (4) fall prevention and frailty assessment, (5) vaccination, (6) atrial fibrillation.

\section{Course Satisfaction}

A summary of course satisfaction ratings is shown in Fig. 1. For modules 1, 2, 3, 4, 5, and 6, percentages of participants reporting minimal prior knowledge of course content were $93.75 \%, 96.34 \%, 98.06 \%$, $98.70 \%, 100 \%$, and $97.65 \%$, respectively; percentages of participants reporting course content being relevant were $100 \%, 96.34 \%, 97.09 \%, 94.81 \%, 97.69 \%, 98.82 \%$, respectively; percentages of participants reporting course content being relevant were $97.92 \%, 96.34 \%, 93.21 \%, 96.10 \%, 98.98 \%$, and $98.82 \%$, respectively, percentages of participants reporting overall course satisfaction were $96.88 \%, 93.90 \%$, $86.41 \%, 84.42 \%, 92.96 \%$, and $92.94 \%$, respectively.

Salient learning points that trainers perceived as relevant to educate GPs regarding promoting healthy ageing in Guangzhou, China

Through group discussion and online survey responses from participants (GP trainers) identified salient points regarding promotion of healthy ageing in China for each of the six topics presented and these are summarized below. 
Module 1: Polypharmacy and de-prescribing

1. Polypharmacy is frequent clinical presentation in general practice in China.

2. Inappropriate polypharmacy is one of the top ten problems identified in Guangzhou GP clinics.

3 .Older adults with several comorbidities are more exposed to the risk of polypharmacy.

4. Medication therapy must be optimized to minimize the risk of adverse drug reactions.

5. All medicines should be prescribed for the purpose of achieving specific therapeutic objectives that have been agreed with the patient.

6. The patient should be motivated to adhere to their regime and competent to safely take medicines as prescribed.

7. The patient's social determinants of health \& lifestyle should be considered when prescribing.

8. There are multiple risk factors for inappropriate polypharmacy, including advanced age, multiple comorbidities, multiple prescribers or pharmacies, self-treatment with over-the-counter medications, a history of hospitalizations and attending practices with poor medication tracking processes, 9. De-prescribing should be recognised as a staged process that includes stopping, stepping down and dose reduction for up to three months with 12 months clinical follow-up.

10. More evidence is needed to guide de-prescribing in the older population.

Module 2: Dementia

1. Dementia is a syndrome, not a disease. It is also an umbrella terminology.

2. Dementia is not just a decline in mental ability affecting memory and thought processes but is often under recognised as including social and behavioural manifestation and affecting daily tasks.

3. The 'head turn sign'[14] may serve as a spot diagnostic tool for clinical screening.

4. Patients should be informed that there are many reversible causes of dementia that can be controlled. 5. Non-pharmacological intervention that should be recommended for dementia prevention include regular physical activity, smoking cessation and key elements of the Mediterranean diet (i.e. fish consumption) adapted for Chinese older adults.

6. A multidisciplinary approach for dementia management should be taken and recognise the important roles of family members and carers.

Module 3: Antibiotic stewardship

1. Tendinopathy is one of the often-overlooked side effects of fluoroquinolones in general practice.

2. Antibiotic stewardship should be promoted in the GP community to improve patient health outcomes, reducing drug resistance and decreasing unnecessary costs.

3. Antibiotics guidelines in general practice should be tailored to the local context.

Module 4: Fall prevention and frailty assessment

1. Frailty is a medical syndrome with increased morbidity and mortality in the older population. Understanding the difference between older age and a diagnosis of frailty is important for GP clinics. 
2. There are many risk factors for falls, while frailty has a genetic basis.

3. Assessment tools useful for clinical screening for falls and frailty should be used.

4. There are many predictable causes of falls. Preventive strategies should be individualized for older patients who present to Chinese GP clinics with a fall.

5. All older patients in China are not presently given information about falls prevention.

6. A Frailty assessment clinic in Australia and its role in delaying or reversing the frailty progress with exercise prescription has shown consistent benefits.

7. The multidisciplinary approach for both fall prevention and frailty management should recognise important roles of general practitioners, nurses, physiotherapists and carers.

Module 5: Vaccination

1. Vaccination for older adults is relatively under-recognized in China.

2. It is necessary to encourage a selected group of older patients to consider vaccination to enhance protection of vulnerable older adults in China.

3. There should be a risk and benefit ratio discussion for the patient before vaccination.

4. There are documented benefits of vaccination in reducing morbidity and mortality.

5. Increasing public awareness of the antigenic drift and shift of the influenza virus should be promoted in community settings in China.

Module 6: Atrial fibrillation

1. The prevalence of atrial fibrillation in older adults in China is increasing.

2. There are multiple risk factors for atrial fibrillation, some of which are controllable at the level of general practice.

3. There are several useful frameworks of clinical assessment for atrial fibrillation, including the CHADS2VASc score[15] and HAS-BLED score[16], which can and should be promoted in general practice.

4. The pros and cons of rate control versus rhythm control strategies for older patients should be discussed.

5. Anticoagulation therapy for stroke prevention is important for older patients, which can and should be managed in general practice.

Subsequently, salient points according to the above six modules were further categorized into three domains including personal, interpersonal, and societal domains to address promotion of healthy ageing in Guangzhou, China. These domains are presented in Table 1 along with illustrative quotes. The Personal domain primarily concerned the knowledge and skills needed to be equipped for the GP trainees. The Interpersonal domain concerned the interaction needed between the GP and the older patient. The Societal domain concerned the coordinated efforts needed by academic societies or society as a whole. 
Table 1

Domains required to address Promotion of Healthy Aging in Guangzhou, China

Modules

Polypharmacy and deprescribing

\section{Salient Points per Domains}

\section{Personal}

- Polypharmacy is a frequent clinical encounter in general practice.

- Inappropriate polypharmacy is one of the top ten problems in GP clinics.

- Older people with several comorbidities are more exposed to the risk of polypharmacy.

- Medication therapy has been optimized to minimize the risk of adverse drug reactions.

- De-prescribing is a lengthy process that includes stopping, stepping down and dose reduction up to three months with 12 months clinical follow-up.

Interpersonal

- All medicines should be prescribed for the purpose of achieving specific therapeutic objectives that have been agreed with the patient.

- The patient should be motivated and able to take all medicines as intended.

- The patients' social determinants of health \& lifestyles should be considered when prescribing.

- There are several risk factors for inappropriate polypharmacy that need to be addressed on an interpersonal level with the patients, e.g. self-treatment with over-the-counter medications, etc.

\section{Societal}

- More evidence is needed to guide deprescribing in the elderly population.

- There are several risk factors for inappropriate polypharmacy that need to be addressed in the wider sociocultural context: practices with poor medication tracking processes

\section{Illustrative Quotes}

In order to avoid inappropriate polypharmacy, the GP needs to be well acquainted with adverse effects and possible interactions of different medications often prescribed for an older patient with multiple comorbidities.

(trainer \#4) 


\begin{tabular}{|c|c|c|}
\hline Modules & Salient Points per Domains & Illustrative Quotes \\
\hline Dementia & $\begin{array}{l}\text { Personal } \\
\text { - Dementia is a syndrome, not a disease. } \\
\text { It is also an umbrella terminology. } \\
\text { - Dementia is not just a decline in mental } \\
\text { ability affecting memory and thought } \\
\text { processes but also a decline in functional } \\
\text { and behavioural capacity of various } \\
\text { domains including motor disturbance, } \\
\text { language defect and social function. } \\
\text { - The 'head turn sign' can serve as a spot } \\
\text { diagnostic tool for clinical screening. } \\
\text { - There are many reversible causes of } \\
\text { dementia that can be controlled. } \\
\text { Interpersonal } \\
\text { - Non-pharmacological intervention for } \\
\text { dementia prevention includes regular } \\
\text { physical activity, smoking cessation and } \\
\text { the Mediterranean diet. } \\
\text { Societal } \\
\text { - A multidisciplinary approach for } \\
\text { dementia management should involve } \\
\text { the important roles of family members } \\
\text { and carers. }\end{array}$ & $\begin{array}{l}\text { "The GP needs to be trained to rule out } \\
\text { organic diseases for older patients } \\
\text { with dementia." (trainer \#3) }\end{array}$ \\
\hline $\begin{array}{l}\text { Antibiotic } \\
\text { stewardship }\end{array}$ & $\begin{array}{l}\text { Personal } \\
\text { - Tendinopathy is one of the often- } \\
\text { overlooked side effects of } \\
\text { fluoroquinolones in general practice. } \\
\text { Societal } \\
\text { - Antibiotic stewardship should be } \\
\text { promoted in the professional community } \\
\text { to improve patient health outcomes, } \\
\text { reducing drug resistance and decreasing } \\
\text { unnecessary costs. } \\
\text { - Data regarding antibiotics usage in } \\
\text { general practice should be collected and } \\
\text { relevant guidelines for GPs should be } \\
\text { developed in China. }\end{array}$ & $\begin{array}{l}\text { It is advisable to collect data } \\
\text { concerning the use of antibiotics in GP } \\
\text { clinics in relation to patient outcomes } \\
\text { in China. } \\
\text { (trainer \#6) }\end{array}$ \\
\hline
\end{tabular}




\begin{tabular}{|c|c|c|}
\hline Modules & Salient Points per Domains & Illustrative Quotes \\
\hline $\begin{array}{l}\text { Fall } \\
\text { prevention } \\
\text { and frailty } \\
\text { assessment }\end{array}$ & $\begin{array}{l}\text { Personal } \\
\text { - Frailty is a medical syndrome with } \\
\text { increased morbidity and mortality in older } \\
\text { adults. } \\
\text { - There are many risk factors for falls, } \\
\text { while frailty has a genetic basis. } \\
\text { - There are assessment tools useful for } \\
\text { clinical screening for fall and frailty. } \\
\text { Interpersonal } \\
\text { - There are many predictable causes of } \\
\text { falls. Prevention strategies should be } \\
\text { individualized. } \\
\text { Societal } \\
\text { - A Frailty assessment clinic in Australia } \\
\text { and its role in delaying or reversing the } \\
\text { frailty progress with exercise prescription } \\
\text { has shown consistent benefits. } \\
\text { - The multidisciplinary approach for both } \\
\text { fall prevention and frailty management } \\
\text { should involve the important roles of } \\
\text { general practitioners, nurses, } \\
\text { physiotherapists and carers. }\end{array}$ & $\begin{array}{l}\text { "The Australian experience of frailty } \\
\text { assessment and fall prevention in the } \\
\text { older populations can inform general } \\
\text { practice in China." (trainer \#7) }\end{array}$ \\
\hline Vaccination & $\begin{array}{l}\text { Personal } \\
\text { - Vaccination in older population is } \\
\text { relatively under-recognized in China. } \\
\text { - There are documented benefits of } \\
\text { vaccination in reducing morbidity and } \\
\text { mortality. } \\
\text { Interpersonal } \\
\text { - It is necessary to encourage selective } \\
\text { older patients to consider vaccination. } \\
\text { - There should be a risk and benefit ratio } \\
\text { discussion with older patients before } \\
\text { vaccination. } \\
\text { Societal } \\
\text { - There should be an increasing public } \\
\text { awareness of the antigenic drift and shift } \\
\text { of the influenza virus. }\end{array}$ & $\begin{array}{l}\text { "Careful history-taking and discussion } \\
\text { of risks and benefits for the older } \\
\text { patients should precede the GP's } \\
\text { recommendation for vaccination." } \\
\text { (trainer \#13) }\end{array}$ \\
\hline
\end{tabular}




\begin{tabular}{|lll|}
\hline Modules & Salient Points per Domains & Illustrative Quotes \\
\hline $\begin{array}{l}\text { Atrial } \\
\text { fibrillation }\end{array}$ & Personal & $\begin{array}{l}\text { "Anticoagulation therapy for atrial } \\
\text { fibrillation, as well as many other } \\
\text { cardiovascular disease prevention } \\
\text { measures, can and should be } \\
\text { managed by GPs in the community." } \\
\text { (trainer \#17) }\end{array}$ \\
older population is on the rise. & \\
- There are many risk factors for atrial & fibrillation, some of which are & \\
controllable at the level of general & practice. \\
& - There are several useful frameworks of \\
clinical assessment for atrial fibrillation, & \\
including the CHADS2-VASc score and & \\
HAS-BLED score, which can and should & \\
be promoted in general practice. & \\
Interpersonal & \\
& - The pros and cons of rate control versus \\
rhythm control strategies for the older & \\
patients should be discussed. & \\
& Societal \\
& - Anticoagulation therapy for stroke \\
prevention can and should be managed & \\
in general practice.
\end{tabular}

\section{Discussion}

Our current study explored whether a train-the-trainer course for local GP trainers could be a means of furthering the promotion of healthy ageing in China. Satisfaction ratings revealed that TTT course was well-received among participants, indicating that this may be an ideal platform for academic exchange. Feedback from the TTT course, identified gaps and needs regarding how GPs can promote healthy ageing and how these concepts of healthy ageing can be incorporated into GP training. The identified themes reflected the current educational context of GP training and also provided valuable insights for future curriculum design as well as actual implementation.

The majority of salient points reported by the local GP trainers as being highly relevant to promote to GPS and the community could be categorised as basic facts and knowledge, corresponding to the cognitive domain according to Bloom's taxonomy[17]. For example, in the module of polypharmacy and deprescribing, trainer \#4 reported that "In order to avoid inappropriate polypharmacy, the GP needs to be well acquainted with adverse effects and possible interactions of different medications often prescribed for an elderly patient with multiple comorbidities." In the past several decades, medical education in China predominately revolved around rigid traditional subjects[18, 19]. Albeit in its infancy, curriculum reform has yielded promising results in recent years, but the traditional emphasis on cognitive skills may still take precedence[20]. Within the larger educational context, general GP training with healthy ageing 
promotion in particular, is still perceived to be primarily, if not exclusively, an intellectual endeavour, as shown in our results. Nevertheless, these salient points are important because they reflect what the local GP trainers consider as current key issues. Hence these results are helpful to inform curriculum design for GP train the trainer programs that can scaffold GPs in China to develop their ability in the community to promote healthy ageing.

There were multiple salient points reported by the local GP trainers that addressed the interpersonal dimension of healthy ageing promotion. For example, in the module of vaccination, trainer \#13 reported "Careful history-taking and discussion of risks and benefits for the elderly should precede the GP's recommendation for vaccination." Since the best course of care for a patient can sometimes be hard to decide, time can be considered as an organizing tool for shared decision-making over longer encounters[21]. General practitioners are thus uniquely positioned in this process because they provide a continuity of care. In a recent study, Price et al. explored the perspectives of older people for their participation in the Australian $75+$ Health Assessment program, which was developed to identify issues for the health and well-being of the elderly in the community. The authors found that a person-centred approach was of paramount importance in enabling older people to make informed decisions and manage their own health and well-being successfully[22]. The challenge for the GP, then, in the promotion of healthy ageing, is to acknowledge the resilience, adaptability and independence of older people so that they can be motivated to achieve their personal goals for ageing. Feedback from local GP trainers pointed to the widespread recognition in China that the modus operandi in medicine had gradually shifted from paternalism to shared decision-making[10], and that such transition of mindset will eventually materialize in what and how the next generation of GPs will be trained.

These local GP trainers also identified that coordinated efforts by academic societies and the society in general are required. For example, in the module of antibiotic stewardship, trainer \#6 reported that "It is advisable to collect data concerning the use of antibiotics in GP clinics in relation to patient outcomes in China." This highlights that the current knowledge gap is both imminent and important and has ramifications for both scientific research and medical education in China. Another group of researchers have also recommended that measures such as surveillance networks, professional personal promotion, training and education, general practitioners are well positioned to take a pivotal role in the national campaign for rational antibiotic use in China[23]. In the module of atrial fibrillation, trainer \#17 reported "Anticoagulation therapy for atrial fibrillation, as well as many other cardiovascular disease prevention measures, can and should be managed by GPs in the community." This recognition of the capability of GPs highlights the need to further China's program of healthcare reform, specifically in building the capacity and capability of an integrated, cooperative primary-care system[10]. Also, in the module of fall prevention and frailty assessment, trainer \#13 reported, "The Australian experience of frailty assessment and fall prevention in the elderly can inform general practice in China." This highlights the prospect of collaboration between institutions in China and Australia for the promotion of healthy ageing in both countries, which prompts participation and commitment in both clinicians and academia as well as in the administrative staff. In general, salient points in the societal domain were directed at the necessity of coordinated efforts for health advocacy in the professional community as well as the wider public. 


\section{Strengths And Limitations}

Strengths of the study were that is provided an authentic on the ground reflection from GP trainers who themselves work in the community in China. Their reflections represent an insider view of the current perspectives in China. To our knowledge, this is the first study to explore GP trainers' perception on their training of GP trainees with regards to the promotion of healthy ageing in China. However, it is limited in the small sample of participants from the metropolitan area in China. Any generalisation of these results should be interpreted with caution.

\section{Conclusion}

The TTT course for GP trainers provided a useful platform for academic exchange regarding healthy ageing promotion in the field of primary care in China. Besides excellent feedback in course satisfaction, with salient points under six geriatric-related issues commonly encountered in general practice were identified. These results may inform future training, research and collaboration initiatives for GPs relevant to their roles as health advocate for the older population.

\section{Declarations}

\section{Ethics approval and consent to participate}

The project has been approved by both the Curtin University Ethics Committee and Sun Yat-sen University Ethics Committee. Online written consents have been obtained from all trainer participants.

\section{Consent for publication}

Consents for publication have been obtained from all authors and participants at both Curtin Medical School, Curtin University, Perth, Australia and the First Affiliated Hospital, Sun Yat-Sen University, Guangzhou, China.

\section{Availability of data and materials}

The datasets analysed during the current study are available from the corresponding author on reasonable request.

\section{Competing interests}

There are no competing interests to be declared. 


\section{Funding}

There is no external funding for the study to be declared.

\section{Authors' contributions}

Daya Yang, Gang Yuan, Hao Tang \& Dan Xu: Substantial contributions to the design of the work; the acquisition, analysis and interpretation of data for the work; Drafting the work, reviewing and revising the work critically for important intellectual content; Final approval of the version to be published; Agreement to be accountable for all aspects of the work in ensuring that questions related to the accuracy and integrity of any part of the work are appropriately investigated and resolved

Anne-Marie Hill, Wei Chen, Jingsong Wang, Ming Kuang \& Haipeng Xiao: Contributions to the design of the work; Reviewing and revising the work critically for important intellectual content; Final approval of the version to be published; Agreement to be accountable for all aspects of the work in ensuring that questions related to the accuracy and integrity of any part of the work are appropriately investigated and resolved

\section{Acknowledgements}

We acknowledge the staff at both Curtin Medical School, Curtin University, Perth, Australia and the First Affiliated Hospital, Sun Yat-Sen University, Guangzhou, China.

\section{References}

1. World Health Organization: Active ageing: a policy framework. 2002. WHO/NMH/NPH/02.8. 2002. Available from: apps.who.int/iris/bitstream/10665/67215/1/WHO_NMH_NPH_02.8.pdf [Accessed Apr. 30, 2020]

2. Baltes PB BM: Successful ageing: Perspectives from the behavioural sciences: Cambridge: Cambridge University Press.; 1990.

3. Bowling A, Dieppe P: What is successful ageing and who should define it? BMJ 2005, 331(7531):1548-1551.

4. Rowe JW KR: Successful Ageing. The Gerontologist 1997, 37:433-440.

5. Kendig H, Browning C: Positive ageing: facts and opportunities. Med J Aust 1997, 167(8):409-410.

6. Baltes M ML: Produktives Leben im Alter.: Frankfurt/Main, New York: Campus.; 1996.

7. European Commission/Joint Research Centre. Joint research centre and policy reports. The role of nutrition in active and healthy ageing. . In: Mak TN CS, editors, ed., 2014. Available from: http://www.mutualearning.net/cms/images/Docs/3_JCR_Nutritionin\%20healthyandactiveageing.pdf [Accessed Apr. 30, 2020] 
8. Fernandez-Ballesteros R M-RN: Toward a definition of "successful" Ageing.: Geburtstag von Ursula Lehr. Heidelberg: AKA; 2020.

9. Lionis C, Midlov P: Prevention in the elderly: A necessary priority for general practitioners. Eur J Gen Pract 2017, 23(1):202-207.

10. Li X, Lu J, Hu S, Cheng KK, De Maeseneer J, Meng Q, Mossialos E, Xu DR, Yip W, Zhang H et al: The primary health-care system in China. Lancet 2017, 390(10112):2584-2594.

11. M. C: The foundations of social research. Meaning and perspective in the research process. : London: Sage publications.; 2003.

12. Thomas J, Harden A: Methods for the thematic synthesis of qualitative research in systematic reviews. BMC Med Res Methodol 2008, 8:45.

13. Ziebland S, McPherson A: Making sense of qualitative data analysis: an introduction with illustrations from DIPEx (personal experiences of health and illness). Med Educ 2006, 40(5):405-414.

14. Fukui T YT, Kinno R. : Can the 'Head-Turning Sign' Be a Clinical Marker of Alzheimer's Disease? . Dement Geriatr Cogn Disord Extra 2011, 1:310-317.

15. Friberg L, Rosenqvist M, Lip GY: Net clinical benefit of warfarin in patients with atrial fibrillation: a report from the Swedish atrial fibrillation cohort study. Circulation 2012, 125(19):2298-2307.

16. Friberg L, Rosenqvist M, Lip GY: Evaluation of risk stratification schemes for ischaemic stroke and bleeding in 182678 patients with atrial fibrillation: the Swedish Atrial Fibrillation cohort study. Eur Heart J 2012, 33(12):1500-1510.

17. Bloom BS EM, Furst EJ., Hill WH., \& Krathwohl DR. : Taxonomy of Educational Objectives - The Classification of Educational Goals - Handbook 1: Cognitive Domain.: London, WI: Longmans, Green \& Co. Ltd.; 1956.

18. Baozhi S, Yuhong Z: Medical curricula in China and the USA: a comparative study. Med Teach 2003, 25(4):422-427.

19. Ren X, Yin J, Wang B, Roy Schwarz M: A descriptive analysis of medical education in China. Med Teach 2008, 30(7):667-672.

20. Huang L, Cheng L, Cai Q, Kosik RO, Huang Y, Zhao X, Xu GT, Su TP, Chiu AW, Fan AP: Curriculum reform at Chinese medical schools: what have we learned? Med Teach 2014, 36(12):1043-1050.

21. Pieterse AH, Stiggelbout AM, Montori VM: Shared Decision Making and the Importance of Time. JAMA 2019, 322(1):25-26.

22. Price K, Grimmer K, Foot J: Is the Australian 75+ Health Assessment person-centred? A qualitative descriptive study of older people's perceptions. Aust Health Rev 2017, 41(6):606-612.

23. Xiao Y: Antimicrobial Stewardship in China: Systems, Actions and Future Strategies. Clin Infect Dis 2018, 67(suppl_2):S135-S141.

\section{Figures}




\section{Course Satisfaction Ratings}

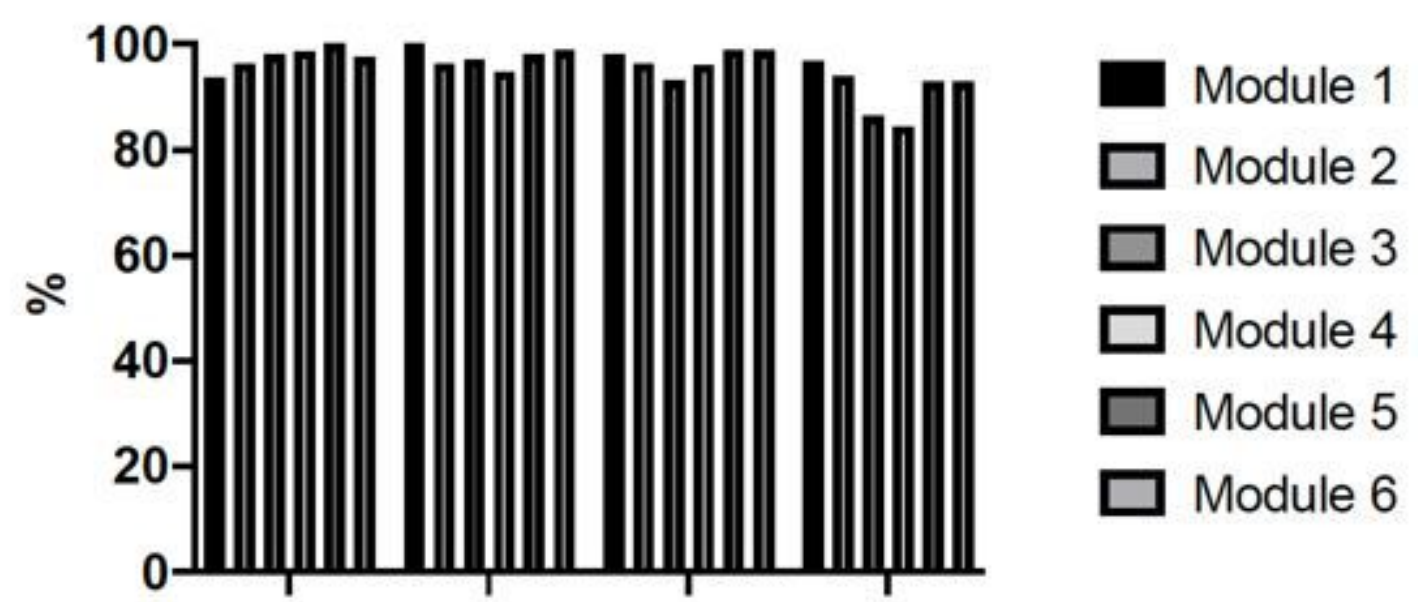

Figure 1

Course satisfaction ratings with 20 Participants Modules 1 to 6 were: (1) polypharmacy and deprescribing, (2) dementia, (3) antibiotic stewardship, (4) fall prevention and frailty assessment, (5) vaccination, (6) atrial fibrillation. 